\title{
Power Component Sizing Based on Power Allocation Strategy for a Fuel Cell/Battery Hybrid Tram
}

\author{
Wenbin Zhang ${ }^{1,3}$, Liangfei $\mathrm{Xu}^{1,4}$, Jianqiu $\mathrm{Li}^{1, *}$, Yuwen $\mathrm{Liu}^{2}$, Qingjun $\mathrm{Han}^{2}$ and Yankun $\mathrm{Li}^{2}$ \\ ${ }^{1}$ Department of Automotive Engineering, State Key Laboratory of Automotive Safety and Energy, Tsinghua University, Beijing \\ 100084, PR China, Collaborative Innovation Center of Electric Vehicles in Beijing, Beijing 100081, PR China \\ ${ }^{2}$ CRRC Qingdao Sifang Co, Ltd, Qingdao 266111, PR China \\ ${ }^{3}$ Department of Scientific Research. Military transportation University, Tianjin 300161, PR China \\ ${ }^{4}$ Institute of Energy and Climate Research, IEK-3: Electrochemical Process Engineering, Forschungszentrum Jülich GmbH, \\ 52425 Jülich, Germany \\ *Corresponding author
}

\begin{abstract}
This paper describes component sizing problem of a tram powered by a hybrid system based on fuel cell system (FCS) and a battery pack. The FCS delivers stationary power while the battery provides dynamic power. In this paper, we report on an optimization problem of powertrain parameters for a pre-defined driving cycle regarding fuel economy and system drivability. A global optimal power allocation strategy based on Pontryagin's Minimal Principle (PMP) is exploited. Simulation results show that for a "typical tram cycle," a battery capacity of $200 \mathrm{Ah}$ and an FCS maximal net output power of $200 \mathrm{~kW}$ are optimal for the fuel economy of a fuel cell/battery tram.
\end{abstract}

Keywords-fuel cell; hybrid tram; pontryagin's minimal principle; power allocation

\section{INTRODUCTION}

Fuel cells, for their merits of high efficiency and practically null emission of polluting agents [1], have currently served as promising power supplies for trams. The North American consortium integrated a $250 \mathrm{~kW}$ fuel cell system (FCS) as prime mover and batteries as auxiliary power in a 1.2 MW large fuel cell hybrid locomotive [2]. The power level of the FCS applied for tram in different countries include: Japan $(120 \mathrm{~kW})$ [3], Italy (120 kW) [4], Spain (150 kW) [5], etc. China's first fuel cell locomotive was introduced in [6]. However, China's first fuel cell tram was first tested by CRRC Qingdao Si-fang Locomotive Co., Ltd together with our group. The tram is powered by a $150 \mathrm{~kW}$ FCS, a $21 \mathrm{kWh}$ Li-ion battery pack and a 500 Wh ultra-capacitor pack [7].

Four problems are concerned for a hybrid system: the driving cycle, the power allocation methods, the hardware architecture and the optimal size [8]. A lot of research are about the power allocation methods, the optimal size or the combination of them [9]. The power allocation methods are applied to define the power sources, and it can be categorized into rule-based and optimization approaches [10]. researchers have investigated the application of various methods including fuzzy logic strategy [11], sliding mode control [12], model predictive control [13], load-following mode control [14], dynamic programming (DP) [15] and convex optimization strategies [16], Equivalent Consumption Minimization Strategies (ECMS) [17] and Pontryagin's Minimum Principle (PMP) strategies [18]. For the component sizing problems,
Sundstrom, et al [19] explored the battery sizing problem of a FCHV by DP under three type of cycles and found the optimal battery size is dependent on the cycle, the vehicle weight, etc. Murgovski, et al [20] simultaneously optimized component sizing and power management of a fuel cell/battery hybrid bus by convex programming. Kim and Peng [21] developed a near-optimal pseudo-stochastic dynamic programming (SDP) energy controller whose parameters can be solved by nonlinear programming, together with the component sizes of a fuel cell/battery hybrid vehicle. Zheng C, et al. [22] present a power source sizing methodology for fuel cell hybrid vehicles considering the vehicle performance and cost. A PMP-based power management strategy is adopted to compare the fuel consumption.

In this research, a power component sizing methodology is proposed for a fuel cell/battery tram targeting at minimizing the fuel consumption and keep the battery charge sustain. The cycle-related power demand is introduced as the drivability constraints on the power component sizing. A PMP-based power allocation strategy is applied to distribute the required power. The sizing problems and the power allocation problems are combined to optimize.

\section{Power-Train Structure Model AND Size Problem}

A. Power-Train Structure

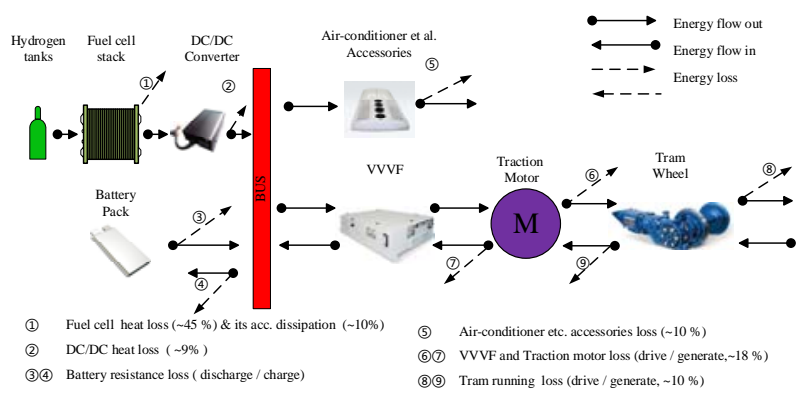

FIGURE I. STRUCTURE AND ENERGY FLOW OF A FUEL CELL HYBRID TRAM [7]

Figure 1 illustrated the hybrid tram structure. It is an non plug-in fuel cell hybrid tram. Divided by the bus, the left is the 
power plant including the FCS and the battery pathway and the right is the motor traction system and the auxiliaries of airconditioner, etc. The main specifications of the powertrain component are reported in Table 1.

\section{TABLE I. FUEL CELL HYBRID TRAM SPECIFICATIONS}

\begin{tabular}{ll}
\hline Tram \& Component & Specifications \\
\hline \multirow{3}{*}{ Tram } & Mass:65.6/79.6 (full/over load with passengers \\
& without FCS and battery); \\
& Maximum operation Speed: $35 \mathrm{~km} / \mathrm{h}$ \\
Hydrogen tank & 6 tanks,19.2 kg \\
Fuel cell stack \& converter & $230 \mathrm{~kW}$ (base selected), <710V \\
& Unidirectional boost DC/DC converter \\
Battery cell \& pack & Cell: 20 Ah,2.3V \\
& Pack: 315 series, 6(base selected) 10 parallels \\
Bus voltage & $560 \sim 900 \mathrm{~V}, \sim 750 \mathrm{~V}$ (normal) \\
Air-conditioner power & $40 \mathrm{~kW}$ \\
Traction motors & 12 motors regulated by 3 Variable Velocity \\
\& converter & Variable Frequency (VVVF) converters; \\
& Each motor: 46.6kW,196 rpm (rated), 706 rpm \\
& (maximum), 2270 Nm(maximum) \\
\hline
\end{tabular}

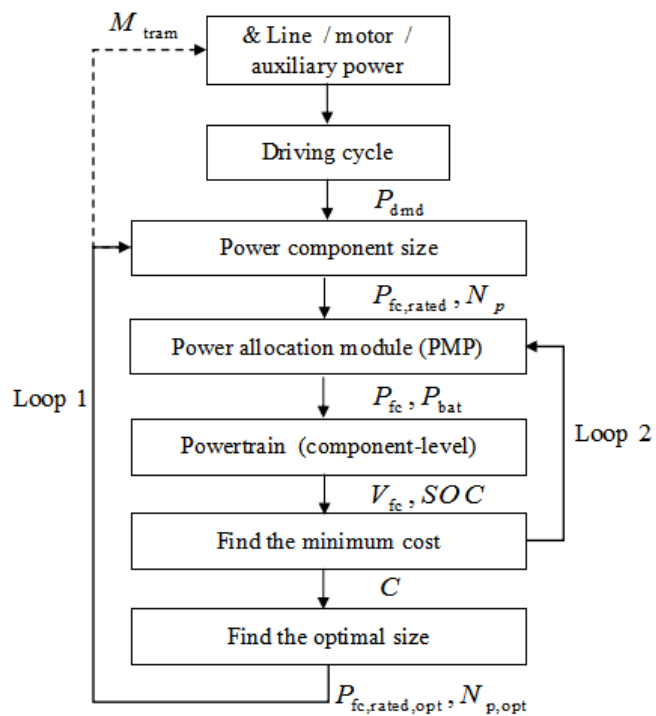

FIGURE II. TWO-LOOP OPTIMIZATION FRAMWORK

Figure 2 shows the two-loop optimization framework where the loop 1 is to find the optimal power component size and the loop 2 is to find the minimum cost based on PMP strategy. The power demand of the cycle $P_{\mathrm{dmd}}$ is calculated based on the tram dynamics which is formulated by forces and speed curve "V-t". Based on the cycle, we choose component size. The rated FCS power $P_{\mathrm{fc}, \text { rated }}$ and the battery parallel number $N_{\mathrm{p}}$ represent the FCS and the battery size, respectively. They are firstly chosen based on the tram roof arrangement though they may be not optimal or even not effective. The operation control module applies the PMP strategy to split the FCS output power $P_{\mathrm{fc}}$ and the battery output power $P_{\text {bat }}$. Then the powertrain shows its characteristics as the FCS output voltage $V_{\text {fc }}$ and the battery state of charge (SOC). By calculating the minimum cost, we find the optimal power allocation between the FCS and the battery. Moreover, comparing the minimum costs in different size, we find the optimal power component size.

\section{B. Component Sizing Considering Drivability Constraints}

The tram power $P_{\text {tram is equal to the motor power }}$ $P_{\mathrm{m}}$,which is the product of total force $F_{\mathrm{drv}}$ and the tram speed $v . F_{\text {drv }}$ is the product of tram mass $\mathrm{M}$ and three coefficients: basic force coefficient $\rho_{0}$, slope force coefficient $\rho_{s}$ and radius force coefficient $\rho_{r}$.

$$
\mathrm{f}_{2}\left(u / u^{t}\right)=1 / 4 \sum_{j-1}^{N} \lambda_{2 j}^{-}\left[2 C_{J} u_{j} / \lambda_{2 j}\right]-\left(C^{+} u^{t}+C^{-} u^{t}\right)
$$

The power demand $P_{\mathrm{dmd}}$ is the sum of the auxiliary power $P_{\text {aux }}$ and the motor power $P_{\mathrm{m}}$ in (1). At the same time, $P_{\mathrm{dmd}}$ is supplied by $P_{\mathrm{fc}}$ and $P_{\mathrm{bat}}$ in (2) where $\eta_{\mathrm{dc}}$ is the DC/DC converter average efficiency. Besides, $P_{\text {bat }}$ is calculated by charge rate C, battery cell capacity $Q_{\text {bat,cell }}$,bus voltage $V_{\text {bus }}$ and $N_{p}$. Then, Changing $\mathrm{C}$ to its maximum value $C_{\max }$, the battery maximum power $P_{\text {bat,max }}$ is obtained.

$$
\begin{aligned}
& P_{\mathrm{dmd}}=P_{\mathrm{fc}} \eta_{\mathrm{dc}}+P_{\mathrm{bat}}, \\
& P_{\text {bat }}=C Q_{\text {bat,cell }} N_{p} V_{\text {bus }}, \\
& P_{\text {bat,max }}=C_{\text {max }} Q_{\text {bat,cell }} N_{p} V_{\text {bus }}
\end{aligned}
$$

Before selecting the best power component size combination for the tram, effective candidates of power component size combinations should be designated according to the tram drivability constraints. The drivability of the tram herein is assessed by the maximum, minimum and average power demand, which are expressed in (3) as $P_{\mathrm{dmd}, \max }$, $P_{\mathrm{dmd} \text {,min }}$ and $P_{\mathrm{dmd}, \text { avg }}$, respectively. The power allocation method tries to balance the battery SOC before and after the cycle. Therefore, the FCS rated power $P_{\mathrm{fc}, \text { rated }}$ is required to provide $P_{\text {dmd,avg }}$. In other words, the minimum FCS size is determined by the average power demand. When the tram is working in the drive mode, the combination of the FCS and the battery should supply $P_{\mathrm{dmd} \text { max }}$. However, for the regenerative mode of the tram, it is selectable for the combination of the power components to offer $P_{\mathrm{dmd} \text {,min }}$. The situation is only for pure electric regeneration. In this tram, hybrid regeneration is applied and $P_{\mathrm{dmd} \text {,min }}$ is omitted. 


$$
\left\{\begin{array}{l}
P_{\mathrm{fc}, \text { rated }} \eta_{\mathrm{dc}}+P_{\mathrm{bat,max}} \geq P_{\mathrm{dmd}, \text { max }} \\
P_{\mathrm{fc}, \text { rated }} \eta_{\mathrm{dc}}+P_{\mathrm{bat}, \text { min }}<P_{\mathrm{dmd}, \text { min }}(\text { selectable }) \\
P_{\mathrm{fc}, \text { rated }} \geq P_{\mathrm{dmd}, \text { avg }}
\end{array}\right.
$$

Considering the component size, the tram mass in (1) is adjusted by (4), adding the FCS mass $M_{\mathrm{fc}}, \mathrm{DC} / \mathrm{DC}$ converter mass $M_{\mathrm{dc}}$ and the battery mass $M_{\text {bat }}$. These mass values are scaled by some base values in (4) and their typical values are shown in Table 2. The mass will modify the power demand values $P_{\mathrm{dmd}, \max }$ and $P_{\mathrm{dmd}, \text { avg }}$.

$$
\begin{aligned}
& M=M_{\text {tram }}+M_{\mathrm{fc}}+M_{\mathrm{dc}}+M_{\mathrm{bat}} \\
& M_{\mathrm{fc}}+M_{\mathrm{dc}}=\left(M_{\mathrm{fc}, \text { base }}+M_{\mathrm{dc}, \text { base }}\right) P_{\mathrm{fc}, \text { rated }} / P_{\mathrm{fc}, \text { rated,base }} \\
& M_{\text {bat }}=M_{\text {bat,base }} N_{\mathrm{p}} / N_{\mathrm{p} \text {,base }}
\end{aligned}
$$

TABLE II. BASE COMPONENT FOR EVALUATING THE COMPONENT MASS ADDED TO THE TRAM

\begin{tabular}{ccc}
\hline Parameter & Symbol & Value \\
\hline FCS base rated power & $P_{\mathrm{fc}, \text { rated,base }}(\mathrm{kW})$ & 230 \\
FCS base mass & $M_{\mathrm{fc}, \text { base }}($ tons $)$ & 1.2 \\
DC/DC converter base mass & $M_{\mathrm{dc} \text {,base }}$ (tons) & 0.8 \\
Battery parallel number & $N_{\mathrm{p}, \text { base }}$ & 6 \\
Battery base mass & $M_{\text {bat,base }}$ (tons) & 2 \\
\hline
\end{tabular}

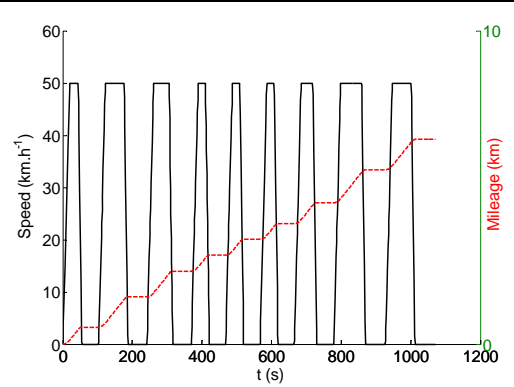

(a)

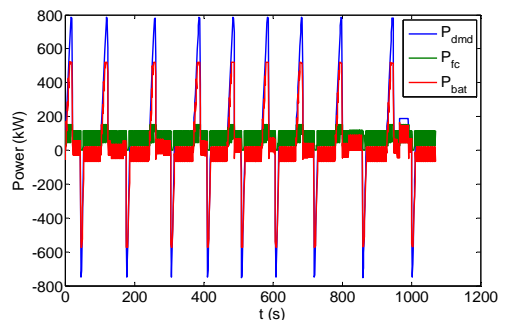

(b)

FIGURE III. EXAMPLE OF ONE CYLCE: (A) SPEED AND MILEAGE; (B) POWER DEMAND AND ALLOCATION
Figure 3(a) gives an example of the cycle-related speed and mileage profiles which maximum speed is $50 \mathrm{~km} / \mathrm{h}$ and the total mileage is $6.57 \mathrm{~km}$. Figure 3(b) presents power demand and the power allocation between the FCS and the battery when base FCS and battery are selected. [ $\left.P_{\mathrm{dmd}, \text { min }}, P_{\mathrm{dmd}, \text { max }}\right]$ is [-752, 786] kW and $P_{\mathrm{dmd}, \text { avg }}$ is about $100 \mathrm{~kW}$. Therefore, the FCS power is set from $100 \mathrm{~kW}$ to 300 $\mathrm{kW}$. The possible of the component size combinations are shown in the shade in Figure 4 while the other area is the impossible region. 12 possible candidates are obtained and listed in Table 3.

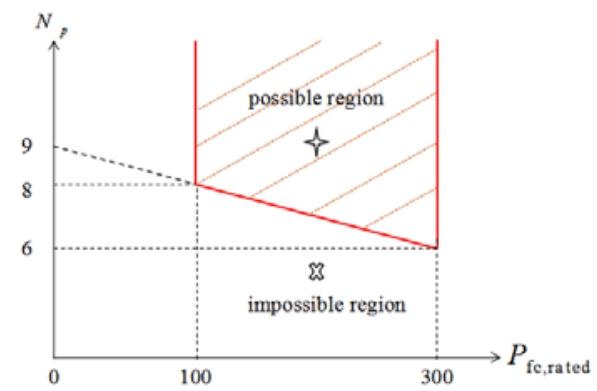

FIGURE IV. EVALUATION REGION OF POWER COMPONENT SIZE COMBINATIONS

TABLE III. EVALUATIONS CANDIDATES OF POWER COMPONENT SIZE COMBINATIONS

\begin{tabular}{cccccc}
$N_{\mathrm{p}}$ & 6 & 7 & 8 & 9 & 10 \\
\hline 100 & & & & & \\
200 & 0 & 1 & 1 & 1 & 1 \\
300 & 1 & 1 & 1 & 1 & 1 \\
\hline
\end{tabular}

\section{Power Plant Model}

FCS is modeled based on experiment curves: $I_{\mathrm{fc}} \sim P_{\mathrm{fc}}$ ( power to current), $V_{\mathrm{fc}} \sim I_{\mathrm{fc}}$ ( current to voltage) and $\eta_{\mathrm{fc}} \sim P_{\mathrm{fc}}$ ( power to efficiency). Different sizes of FCS are modeled by different rated power $P_{\mathrm{fc} \text {,rated }}$. Figure 4 illustrates characteristics of a $230 \mathrm{~kW}$ FCS.

The hydrogen mass flow rate $\dot{m}_{\mathrm{H}_{2}}(\mathrm{~g} / \mathrm{s})$ can be calculated by Eq.(5), where LHV is the low heart value of hydrogen (120 $\mathrm{kJ} / \mathrm{g})$. The hydrogen mass flow $m_{\mathrm{H}_{2}}$ (g) is the integer of $\dot{m}_{\mathrm{H}_{2}}$ by time.

$$
\dot{m}_{\mathrm{H} 2}=\frac{P_{\mathrm{fc}}}{L H V \eta_{\mathrm{fc}}}
$$




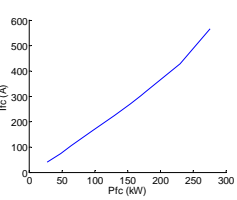

(a)

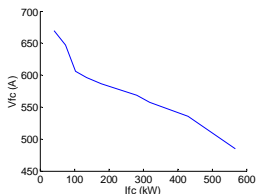

(b)

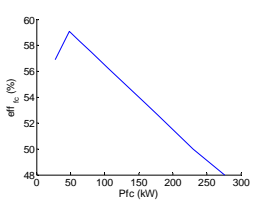

(c)
FIGURE V. FCS MODEL:(A) POWER TO CURRENT CURVE; (B) CURRENT TO VOLTAGE CURVE; (C) POWER TO EFFICIENCY CURVE

The RC equivalent circuit is applied for the battery model. The internal resistance ( $R_{\text {bat }}$ ) and the open circuit voltage ( $V_{\text {ocv }}$ ) of one battery module versus the battery state of charge (SOC) are as shown in Figure 5. Different sizes of batteries share the same voltage and have different capacities or parallel numbers $N_{\mathrm{p}}$. The battery current $I_{\text {bat }}$ can be calculated by the circuit power distribution in (6). The battery SOC is defined as the rate of current capacity to rated capacity $Q_{\text {bat }}$ in (8) where $\eta_{\text {bat }}$ is the battery efficiency in (7).

$$
I_{\mathrm{bat}}=\frac{V_{\mathrm{ocv}}-\sqrt{V_{\mathrm{ocv}}^{2}-4 R_{\mathrm{bat}} \cdot P_{\mathrm{bat}}}}{2 R_{\mathrm{bat}}}
$$

$$
\eta_{\mathrm{bat}}=\left\{\begin{array}{l}
\frac{1}{2}\left(1+\sqrt{\left.1-\frac{4 R_{\mathrm{bat}, \mathrm{dis}} P_{\mathrm{bat}}}{V_{\mathrm{ocv}}^{2}}\right)}, P_{b a t} \geq 0\right. \\
2 /\left(1+\sqrt{1-\frac{4 R_{\mathrm{bat}, \mathrm{chg}} P_{\mathrm{bat}}}{V_{\text {ocv }}^{2}}}\right), P_{b a t}<0
\end{array}\right.
$$

$$
S O C=S O C_{0}-\int \eta_{\text {bat }} I_{\text {bat }} d t / Q_{\text {bat }}
$$

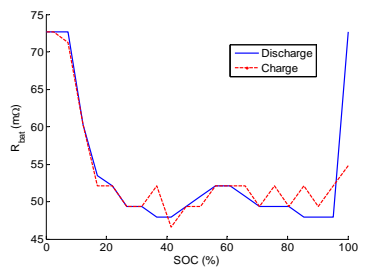

(a)

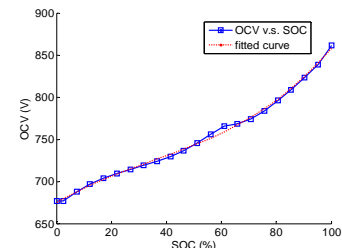

(b)
FIGURE VI. BATTERY MODEL:(A) SOC TO DISCHARGE/CHARGE RESISTANCE CURVE ( $N_{\mathrm{p}}=6$ ); (B) SOC TO OCV CURVE AND THE FITTED CURVE

\section{SimUlation RESUlTS AND DisCUSSION}

In this section, the problem has been defined in the PMP form. The cycle influence on the PMP co-state is discussed. Then, the proposed PMP strategy is applied for the 12 component size combinations in Table 3 and the best one is selected based on the fuel consumption comparison.

\section{A. PMP Strategy}

According to the PMP, the optimal power $P_{\mathrm{fc}}$ meets the following Equation.

$$
\begin{gathered}
P_{\mathrm{fc}}^{*}=\min \left(H_{\mathrm{k}}\right) \\
\left\{\begin{array}{l}
H_{k}=C_{\mathrm{fc}, \mathrm{k}}+C_{\mathrm{bat}, \mathrm{k}}-\lambda I_{\mathrm{bat}, \mathrm{k}} / Q_{\mathrm{bat}} \\
\min (H)=\min \sum_{k=1}^{N} H_{k}
\end{array}\right.
\end{gathered}
$$

The cost function is a Hamiltonian function in (10) where $\mathrm{k}$ is the control steps of the cycle, $\mathrm{N}$ is the total length, ${ }_{k}$ is the instantaneous cost and $H$ is the cycle total cost. $C_{\mathrm{fc}, \mathrm{k}}$ and $C_{\text {bat,k }}$ are the FCS hydrogen consumption cost and the battery electricity cost, respectively; $\lambda$ is the co-state variable. By our former research [18], its solution is expressed as (11) where a, b and c are fitted parameter of from SOC to $V_{\text {ocv }}$ as the fitted curve in Figure 5 (b) shows.

Equation (12) can be solved when the co-state variable initial value $\lambda_{0}$ is known. $\lambda_{0}$ contains driving cycle information in the optimization problem. The trajectory of the battery SOC is closely related to its value.

$$
\dot{\lambda}=\frac{\lambda \eta_{\mathrm{bat}} I_{\mathrm{bat}}\left(3 a S O C^{2}+2 b S O C+c\right)}{Q_{\mathrm{bat}} \sqrt{V_{\mathrm{ocv}}^{2}-4 R_{\mathrm{bat}} \cdot P_{\mathrm{bat}}}}
$$

B. SOC Trajectories with the Co-State Variable Initial Value

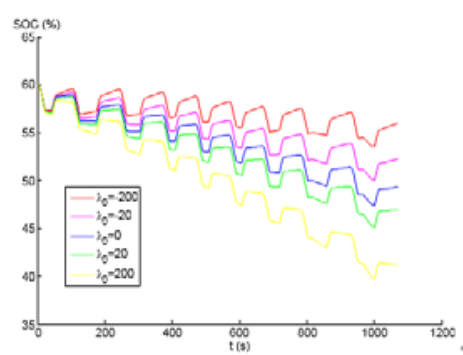

(a)

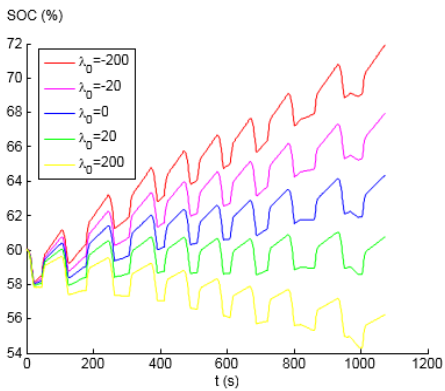

(b) 


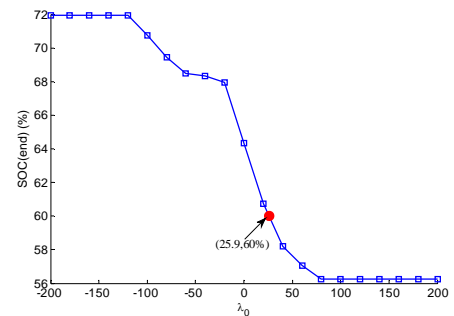

(c)

FIGURE VII. INFLUENCE OF $\lambda_{0}$ ON THE PMP STRATEGY:

BATTERY SOC TRAJECTORIES WITH DIFFERENT $\lambda_{0}$ FOR

CYCLE SETTINGS ABOUT TRAM MASS: (A) 83.9 TONS; (B) 65.9 TONS; (C) THE RELATIONSHIP BETWEEN SOC(END) AND $\lambda_{0}$ FOR CYCLE SETTINGS OF (B)

For the same component size, with different $\lambda_{0}$, the SOC trajectories is present in Figure 7 (a) and (b) under different cycles with different tram mass. Obviously, for the cycle in Figure 5 (a), the tram is heavy loaded and has a considerable power demand. Adjusting $\lambda_{0}$ between -200 and 200, it cannot keep the battery SOC charge sustain at its initial value $60 \%$. However, the situation with lower load in Figure 7 (b) will guide us to find a suitable $\lambda_{0}=25.9$ to guarantee the battery charge sustain, as Figure (c) marks the point.

C. Cost Comparison with the Co-State Variable Initial Value

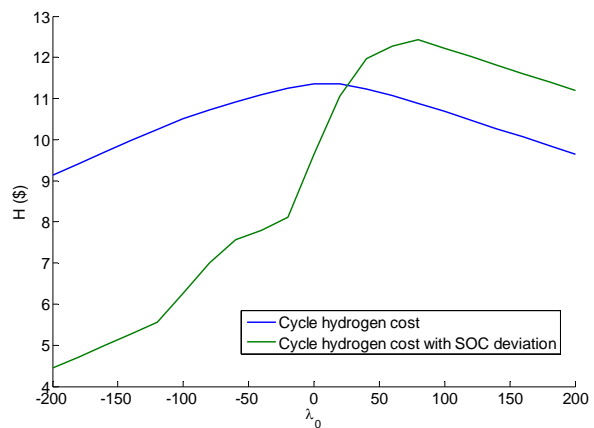

FIGURE VIII. CYCLE HYDROGEN COST AND ITS COMPENSATION WITH SOC DEVIATION UNDER DIFFERENT $\lambda_{0}$

$$
\begin{aligned}
& H^{\prime}=H+H_{\mathrm{SOC}} \\
& H_{\mathrm{SOC}}=\frac{K_{\mathrm{h} 2}\left(S O C_{\mathrm{end}}-S O C_{\mathrm{ini}}\right) Q_{\mathrm{bat}} V_{\mathrm{bus}}}{\eta_{\mathrm{fc}} \eta_{\mathrm{dc}} L H V}
\end{aligned}
$$

Figure 8 gives the cycle hydrogen cost under different $\lambda_{0}$ using (11). However, as Figure 7(c) shows, the SOC end value are different, a fair comparison of the cost can be made after compensating the SOC deviation expressed as $H_{\mathrm{SOC}}$. Hamiltonian function $H$ in (10) has been rewritten as $H^{\prime}$ in
(12) where $K_{\mathrm{h} 2}$ is the hydrogen price $6.5 \$ / \mathrm{kg}$, $S O C_{\text {end }}$ is the battery end values which are also illustrated in Figure 7 (b) and (c), $S O C_{\text {ini }}$ is the battery initial value $60 \%$.

After compensation with the SOC deviation, the cost is lower when $\lambda_{0}<25.9$ and higher when $\lambda_{0}>25.9$, shown in Figure (8). The minimum cost is seen when $\lambda_{0}$ is the minimum value in its scope. However, in this research we set $\lambda_{0}$ as 25.9 to ensure the battery charge sustain as far as possible for there is no charging facilities in the rail line by now.

\section{Cost Comparison with Different Power Component Size}

Figure 9 presents the cycle cost for 12 power component size candidates in Table 3 . If the SOC deviation is not considered, the 4th candidate (200 kW FCS/140 Ah battery) has the lowest cycle cost; if the SOC deviation is added, the 7 th candidate (200 kW FCS/200 Ah battery) is the best one.

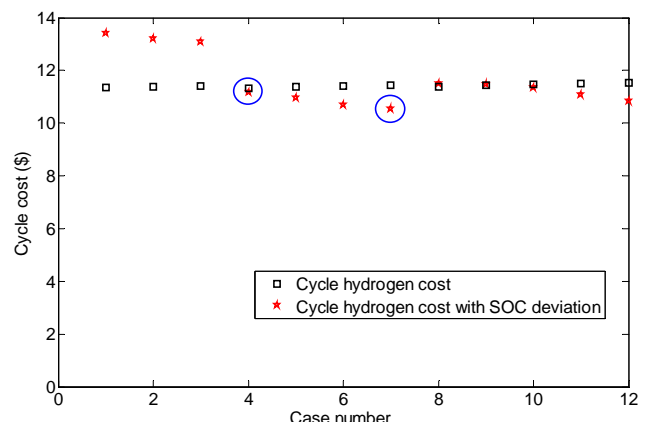

FIGURE IX. CYCLE HYDROGEN COST AND ITS COMPENSATION WITH SOC DEVIATION FOR 12 POWER COMPONENT SIZE CANDIDATES IN TABLE 3

\section{CONCLUSIONS}

A power component sizing methodology is proposed for a fuel cell/battery tram. It is a double loop structure combined size problem and power allocation problem. The PMP strategy is implemented to split the FCS and battery power. The optimal split is searched when the Hamiltonian cost function is the minimum. Cycle-related power demand is used to choose effective candidates of power component size combinations. 12 combinations are chosen and evaluated. The best combination is selected among effective power component size combinations considering the fuel economy together with the battery charge sustain. A $200 \mathrm{~kW}$ FCS and a $200 \mathrm{Ah}$ battery are regarded as the best solution for this hybrid tram.

\section{ACKNOWLEDGMENTS}

This work is supported by National Natural Science Foundation of China (Grant No. 51576113 and U1564209), Ministry of Science and Technology of China (Grant No. 2015BAG06B01), and Tsinghua University (the independent research plan Z02-1 Grant No. 20151080411) and CRRC Qingdao Sifang Co., Ltd (Grant No. SF/JS-LiangZi-2014-542). 


\section{REFERENCES}

[1] Mierlo J, Maggetto G, Lataire P. Which energy source for road transport in the future? A comparison of battery, hybrid and fuel cell vehicles. Energy Convers Manage 2006;47(17):2748-60

[2] Miller AR, Peters J, Smith BE, Velev OA. Analysis of fuel cell hybrid locomotives. J Power Sources 2006; 157(2):855-61.

[3] East Japan Rail Company. Development of the world's first fuel cell hybrid railcar, April 2006. http://www.jreast.co.jp/e/press/20060401.

[4] P. Mugnetti, S.Carbone, G. Pede. A Fuel Cell Switcher Locomotive with a Hybridized Propulsion System.IEEE,2006.

[5] Garcia P, Fernandez LM, Torreglosa JP, Jurado F. Operation mode control of a hybrid power system based on fuel cell/battery/ultracapacitor for an electric tramway. Comput Electr Eng 2013;39:1993-2004. doi:10.1016/j.compeleceng.2013.04.022.

[6] Fei P, Chen W R, Liu Z, Li Q, Dai C. System integration of China's first proton exchange membrane fuel cell locomotive. Int J Hydrogen Energy 2014;39(25): 13886-93

[7] Zhang W, Li J, Xu L, Ouyang M, Liu Y, Han Q, et al. Comparison study on life-cycle costs of different trams powered by fuel cell systems and others. Int J Hydrogen Energy, 2016.

[8] Xu L, Mueller CD, Li J, Ouyang M, Hu Z. Multi-objective component sizing based on optimal energy management strategy of fuel cell electric vehicles. Applied Energy 2015;157: 664-74.

[9] Hu X, Murgovski N, Johannesson LM, Egardt B. Optimal Dimensioning and Power Management of a Fuel Cell/Battery Hybrid Bus via Convex Programming. Journal of Business Ethics 2015;20(1): 457-468.

[10] Xu L, Li J, Ouyang M. Energy flow modeling and real-time control design basing on mean values for maximizing driving mileage of a fue cell bus. Int J Hydrogen Energy 2015;40(43):15052-66.

[11] Caux S, Hankache W, Fadel M, Hissel D. On-line fuzzy energy management for hybrid fuel cell systems. Int J Hydrogen Energy 2010;35:2134-43.

[12] Ayad MY, Becherif M, Henni A. Vehicle hybridization with fuel cell, supercapacitors and batteries by sliding mode control. Renew. Energy 2011;36:2627-34

[13] Amin, Bambang RT, Rohman AS, Dronkers CJ, Ortega R, Sasongko A. Energy management of fuel cell/battery/supercapacitor hybrid power sources using Model Predictive Control. IEEE Trans. Industr. Inform 2014;10:1192-2002.

[14] Bizon N. Load-following mode control of a standalone renewable/fue cell hybrid power source. Energy Convers Manag 2014;77:763-72. doi:10.1016/j.enconman.2013.10.035.

[15] Hu Z, Li J, Xu L, Song Z, Fang C, Ouyang M, et al. Multi-objective energy management optimization and parameter sizing for proton exchange membrane hybrid fuel cell vehicles. Energy Convers Manag 2016;129:108-21. doi:10.1016/j.enconman.2016.09.082.

[16] Hu X, Johannesson L, Murgovski, N, Egardt, B. Longevity-conscious dimensioning and power management of the hybrid energy storage system in a fuel cell hybrid electric bus. Appl. Energy 2015;137, 913924

[17] Han J, Park Y, Kum D. Optimal adaptation of equivalent factor of equivalent consumption minimization strategy for fuel cell hybrid electric vehicles under active state inequality constraints. J Power Sources 2014; 267: 491-502.

[18] Xu L, Ouyang M, Li J, Yang F, Lu L, Hua J. Application of Pontryagin's Minimal Principle to the energy management strategy of plugin fuel cell electric vehicles. Int J Hydrogen Energy 2013; 38(24): 10104-115.

[19] Sundstrom O, Stefanopoulou A. Optimum battery size for fuel cell hybrid electric vehicle with transient loading consideration-Part II. Journal of Fuel Cell Science and Technology 2007; 4(2): 176-184.

[20] Murgovski N, Johannesson L, Sjoberg J, Bo E. Component sizing of a plug-in hybrid electric powertrain via convex optimization. Mechatronics 2012;22(1): 106-120.

[21] Kim MJ, Peng H. Combined control/plant optimization of fuel cell hybrid vehicles. American Control Conference 2006.

[22] Zheng C, Xu G, Jeong J, Cha SW, Park YI, Lim W. Power source sizing of fuel cell hybrid vehicles considering vehicle performance and cost.
International Journal of Precision Engineering and Manufacturing 2014;15(3): 527-533. 